\title{
Zangfu zheng (patterns) are associated with clinical manifestations of zang shang (target-organ damage) in arterial hypertension
}

\author{
Alexandre Bastos Luiz ${ }^{1 \dagger}$, Ivan Cordovil ${ }^{2}$, José Barbosa Filho ${ }^{3}$ and Arthur Sá Ferreira ${ }^{4^{* \dagger}}$
}

\begin{abstract}
Background: Hypertension is a clinical condition that manifests target-organ damage (TOD) with symptoms. This study investigates the association between Zangfu patterns and symptomatic manifestations of TOD.

Methods: Datasets with manifestations of Zangfu patterns (Liver-fire blazing upwards; Kidney-yin deficiency and Liver-yang rising; obstruction of phlegm and dampness of Heart/Liver/Gallbladder; qi and blood deficiency leading to Liver-yang rising; Kidney-yin/yang deficiency) and TODs (cerebrovascular, heart and kidney) were compiled from literature. The Pattern Differentiation Algorithm was used to test and to determine diagnostic accuracy with these datasets. A questionnaire was developed from datasets and applied to 43 subjects newly diagnosed with hypertension. Pattern differentiation was performed and the results were statistically analyzed for association between descriptions of patterns and TOD.

Results: The observed diagnostic accuracy, sensitivity and specificity were 98.0\%, 96.2\% and $99.8 \%$ respectively. Similarity between patterns and TOD datasets was mostly negligible. Twelve manifestations demonstrated high prevalence, namely red tongue (81.4\%), headache (72.1\%), irritability (67.4\%), palpitation (60.5\%), blurred vision, insomnia and mental fatigue (58.1\%), frequent nocturnal urination, numbness in feet and hands, shortness of breath (55.8\%), and heavy limbs sensation, wiry pulse (51.2\%). No significant association was found between blood pressure variables (systolic, diastolic, mean, pulse pressure) and manifestations.
\end{abstract}

Conclusion: Zangfu patterns are associated with clinical manifestations of TOD. Manifestations associated patterns indicate morbid conditions to be secondary to hypertension rather than simple blood pressure.

\section{Background}

\section{Morbidity research on diseases and patterns}

Ancient Chinese medicine literature [1-4] is rich in records of patterns, the Chinese medicine nosological counterpart of disease. Morbidity studies based on Chinese medicine clinical records enhanced practitioner development and training that lead to improved patient care, research programs, public policy and evidencebased commissioning $[5,6]$.

In contemporary Chinese medicine literature [7-12], diseases were assigned to patterns based on matched 'signs and symptoms' (ie manifestations) to integrate

\footnotetext{
* Correspondence: arthur_sf@ig.com.br

† Contributed equally

${ }^{4}$ Program of Rehabilitation Science, Centro Universitário Augusto Motta,

Praça das Nações 34, Bonsucesso, Rio de Janeiro, BR CEP 21041-010, Brazil

Full list of author information is available at the end of the article
}

both medical practices. For instance, studies were conducted in the last two decades for cervical spine cancer (254 cases) [13], frequently recurring cystitis (61 women) [14], hepatocyrrhosis (223 cases [15] and 147 cases [16]), and gastric cancer (767 cases) [17]. Morbidity research of disease-related patterns was advised to focus on public health disorders such as cardiovascular diseases, the principal cause of death in modern society [18].

\section{Chinese medicine patterns in cardiovascular diseases}

Morbidity studies were conducted for variant angina pectoris (175 cases) [19], stable angina pectoris (251 cases) [20] and acute ischemic stroke (1246 cases) [21]. Despite the worldwide high prevalence of hypertension as the major risk factor for cardiovascular diseases [18], only five Chinese medicine morbidity studies on it were found in literature. As Chinese medicine diagnosis could

\section{() Biomed Central}

(c) 2011 Luiz et al; licensee BioMed Central Ltd. This is an Open Access article distributed under the terms of the Creative Commons Attribution License (http://creativecommons.org/licenses/by/2.0), which permits unrestricted use, distribution, and reproduction in any medium, provided the original work is properly cited. 
improve efficacy and/or diminish adverse effects of antihypertensive agents [22], the morbidity of patterns in hypertension must be studied.

Kalish et al. [23] reported the Stop Hypertension with the Acupuncture Research Program trial (a pilot randomized clinical trial on the efficacy of acupuncture in treating essential hypertension), which was expected to find Zangfu patterns in hypertension. A randomized controlled trial [24] on acupuncture treatment for hypertension enrolled 192 patients and the frequency of Zangfu patterns was recorded. However, no data related to observed manifestations were given and no association was investigated between clinical findings ( $e g$ blood pressure) and patterns. Flachskampf et al. [25] randomized the allocation of 160 outpatients with uncomplicated hypertension in a single-blind fashion to a 6-week course of acupuncture intervention; however, they did not report descriptive statistics on patterns or manifestations or association analysis. Chu et al. [26] reported 59 cases of hypertension classified according to whether or not abundant phlegm-dampness was presented for analysis of proteome. Again, no analysis was conducted to explore the frequency distribution of patterns or its manifestations. Gu et al. [27] investigated the frequency distributions of patterns in 477 untreated subjects with hypertension and did not find statistical significance in the frequency distributions of patterns within blood pressure levels, age or body mass index (BMI). This heterogeneity of analysis regarding patterns in subjects with hypertension led to the reports of opposite results of acupuncture treatment for lowering mean 24-hour ambulatory blood pressures.

\section{Diagnosis and prognosis of hypertension in Chinese medicine and conventional medicine}

As hypertension may be symptomless until late in its course, previous guidelines for management of hypertension advised that its diagnosis should be based on multiple systolic (SBP) and diastolic blood pressure (DBP) measurements ( $\geq 140$ and $90 \mathrm{mmHg}$ respectively) taken on separate occasions over time [28]. A recent study indicated that both family and clinical histories would be required for prognosis in patients with high blood pressure [29]. Current knowledge of hypertension emphasizes the role of structural changes in microcirculation (such as arteriolar rarefaction [30,31]) in hypertension pathogenesis and hypertension-related organ damage [32]. Concomitantly, hypertrophied or remodeled medium-sized vessels [33] and stiffened large arteries [34] are the basis of hypertension-induced organ damage in the brain (and eyes), heart or kidneys [32]. In general, changes in blood flow and pressure are not significant until approximately $50 \%$ of the vessel diameter is obstructed [35]. Thus, hypertensive patients' manifestations may indicate the progression or worsening of those target-organ damages (TOD).

On the other hand, Chinese medicine practitioners rely on information collected from the Four Methods (FM, sizhen) of examination, namely inspection (wang), auscultation and olfaction (wen), inquiry (wen) and palpation (qie), and do not use blood pressure measures for pattern differentiation on patients with hypertension. Contemporary literature on Chinese medicine diagnosis [7-12] and clinical research [23,24,27] assign up to five Zangfu patterns to hypertension based only on manifestations. This discrepancy between Chinese medicine and conventional medicine raises the question whether patterns are indeed related to high blood pressure levels or to TOD caused by chronic hypertension. However, no previous study on morbidity of hypertension-related patterns [23-27] has explored the relations between patterns and TOD.

This study investigates the association between Zangfu patterns and clinical manifestations of TOD and tests a hypothesis that patterns are associated with TOD as manifestations associated patterns indicate morbid conditions to be secondary to hypertension rather than simple blood pressure.

\section{Methods}

\section{Study design}

The design of the present study is described in Figure 1. Literature review of patterns and TOD was performed to generate datasets for Chinese medicine and conventional medicine. The diagnostic accuracy of Pattern Differentiation Algorithm (PDA) for Chinese medicine diagnosis was tested for the constructed hypertension dataset. A questionnaire for clinical assessment of patients was generated from hypertension dataset and applied to subjects with hypertension (according to electronic health records). Statistical analysis was conducted to test the association between descriptions of patterns and TOD. The present study followed the guidelines for the Strengthening the Reporting of Observational Studies in Epidemiology (STROBE) [36].

\section{Development of pattern dataset and questionnaire}

Patterns were collected from contemporary literature [7-12,23,24,27], according to which, five Zangfu patterns describing subjects with hypertension are as follows. Liver-fire blazing upwards (gan huo shang yan); Kidneyyin deficiency and Liver-yang rising (shen yin xu gan yang shang yan); Obstruction of phlegm and dampness of Heart/Liver/Gallbladder (xin gan dan shi tan bi); Qi and blood deficiency leading to Liver-yang rising (qi xue xu gan yang shang yan); and Kidney-yin/yang deficiency (shen yin yang $x u$ ). These patterns had their respective manifestations annotated according to the FM to 


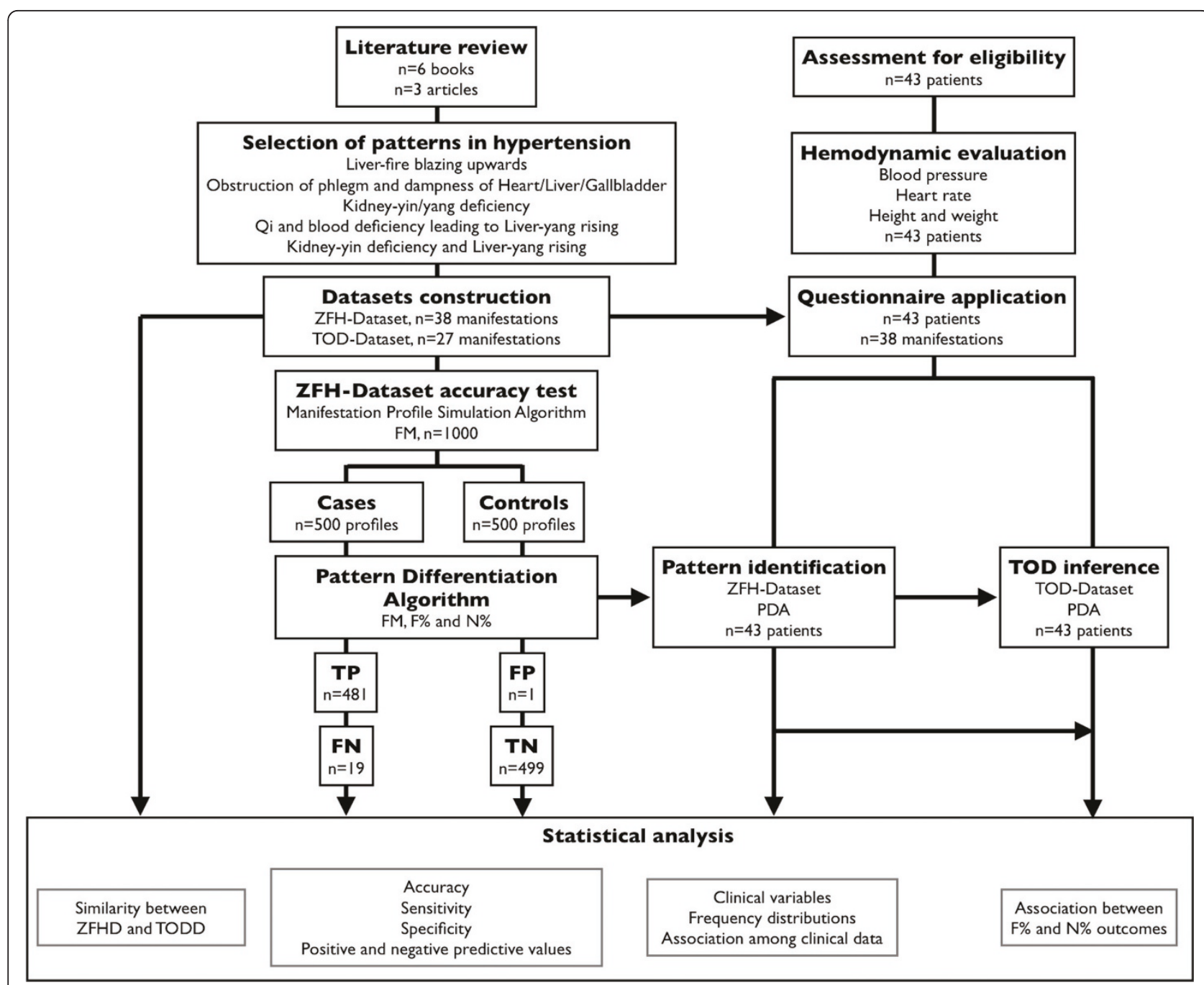

Figure 1 Study design. Literature review of Zangfu patterns and TOD was performed to generate both datasets and questionnaire. A computer-based method for CM diagnosis was validated for the constructed hypertension dataset. The questionnaire was applied to patients and the results were analyzed test the association between Zangfu patterns and TOD.

compose the widest description of each pattern, namely Zangfu hypertension dataset (ZFHD, Table 1). Possible descriptions to distinguish manifestations included its onset, duration, location, progression and severity (Additional file 1).

The questionnaire was automatically generated from ZFHD by an algorithm as follows. Since patterns may share manifestations (co-occurrence of terms), all patterns in ZFHD were merged and their respective manifestations cited only once. Then, the dataset was submitted to a twostage processing scheme for intra-pattern and inter-pattern quality control $[37,38]$. The resulting Zangfu hypertension questionnaire (ZFHQ) was composed of 38 manifestations distributed among inspection $(n=7$; $18.4 \%)$, auscultation-olfaction $(n=2 ; 5.3 \%)$, inquiry ( $n=$ $23 ; 60.5 \%)$ and palpation $(n=6 ; 15.8 \%)$.

\section{Development of TOD dataset: Correspondence between} patterns and TOD

To analyze the association between descriptions of patterns and TOD, we redistributed the manifestations in ZFHD per target-organ within each examination method to compose the TOD dataset (TODD, Table 1). Most of the signs and symptoms describing patterns were easily recognized as corresponding to cerebrovascular, heart or kidney lesions [29,39-47]; however, some manifestations particularly related to tongue inspection and pulse palpation due to predominant qualitative descriptions were not explored [48]. In this study, the following manifestations were assigned based on the argument that a strong correlation $(r=0.74 ; P=0.001)$ was found between a thick yellow or gray tongue coating and halitosis resulting from infection with specific 
Table 1 Chinese medicine patterns of systemic arterial hypertension

\begin{tabular}{|c|c|c|c|}
\hline Examination method & Manifestations & Patterns & Target-organs \\
\hline \multirow[t]{7}{*}{ Inspection } & Flushed face & $A[8,24]$ & * \\
\hline & Grease and thick coating & $C[8,24]$ & $\mathrm{CVD}[51], \mathrm{HD}[51]$ \\
\hline & Pale tongue & $E[8,24]$ & $\mathrm{KD}[43,53]$ \\
\hline & Peeled tongue & $\mathrm{B}[24]$ & * \\
\hline & Red eyes & $A[8]$ & $\mathrm{CVD}[40], \mathrm{KD}[41]$ \\
\hline & Red tongue & $\mathrm{A}[10,24], \mathrm{B}[8,24]$ & * \\
\hline & Yellow coating & $A[8,24]$ & $\mathrm{CVD}[51], \mathrm{HD}[51]$ \\
\hline \multirow[t]{2}{*}{ Auscultation-Olfaction } & Aphasia & $\mathrm{D}[8]$ & CVD[47,43] \\
\hline & Shortness of breath & $E[8,24]$ & $\mathrm{HD}[47,43]$ \\
\hline \multirow[t]{23}{*}{ Inquiry } & Blurred vision & $\mathrm{B}[8,24]$ & $\mathrm{CVD}[47], \mathrm{KD}[44]$ \\
\hline & Congested feeling in the chest & $C[8,24]$ & $\mathrm{HD}[47]$ \\
\hline & Constipation & $A[8,24]$ & $\mathrm{KD}[45]$ \\
\hline & Convulsions & $\mathrm{D}[8]$ & CVD $[44,43]$ \\
\hline & Dizziness & $\mathrm{B}[8,24], \mathrm{C}[8], \mathrm{E}[24]$ & $\mathrm{CVD}[47]$ \\
\hline & Excessive dreaming & $\mathrm{B}[8]$ & * \\
\hline & Fainting & $\mathrm{D}[8]$ & $\mathrm{CVD}[44]$ \\
\hline & Frequent nocturnal urination & $E[8,24]$ & $\mathrm{KD}[44]$ \\
\hline & Headache & $\mathrm{A}[8,10,24], \mathrm{B}[24], \mathrm{D}[8]$ & $\mathrm{CVD}[47,44], \mathrm{KD}[44]$ \\
\hline & Heavy limbs sensation & $C[8]$ & $\mathrm{CVD}[52]$ \\
\hline & Impotence & $E[8,24]$ & * \\
\hline & Insomnia & $\mathrm{B}[8,24]$ & $\mathrm{CVD}[48], \mathrm{HD}[48], \mathrm{KD}[48]$ \\
\hline & Irritability & $A[8,10,24]$ & * \\
\hline & Mental fatigue & $E[8,24]$ & $\mathrm{KD}[45]$ \\
\hline & Nausea & $C[8,24]$ & $\mathrm{CVD}[44,43], \mathrm{KD}[46]$ \\
\hline & Numbness in feet and hands & $E[8]$ & CVD $[47,43]$ \\
\hline & Numbness in the limbs & $\mathrm{B}[8,24], \mathrm{C}[8]$ & CVD[47,43] \\
\hline & Palpitation & $C[8]$ & $\mathrm{HD}[47,43]$ \\
\hline & Severe dizziness & $\mathrm{D}[8,24]$ & $\mathrm{CVD}[47]$ \\
\hline & Stroke & $\mathrm{D}[8]$ & CVD $[47,43]$ \\
\hline & Tinnitus & $\mathrm{A}[10], \mathrm{B}[8,24], \mathrm{E}[8,24]$ & $\mathrm{CVD}[42]$ \\
\hline & Vomiting & $C[8]$ & $\mathrm{CVD}[52], \mathrm{KD}[46]$ \\
\hline & Weak legs & $\mathrm{E}[8]$ & $\mathrm{CVD}[47,43], \mathrm{KD}[44]$ \\
\hline \multirow[t]{6}{*}{ Palpation } & Deep pulse & $E[8,24]$ & * \\
\hline & Fast pulse & $\mathrm{A}[8,24], \mathrm{B}[8,24]$ & $\mathrm{HD}[47]$ \\
\hline & Slippery pulse & $C[8,24]$ & * \\
\hline & Strong pulse & $A[8]$ & * \\
\hline & Thin pulse & $\mathrm{B}[8], 24, \mathrm{E}[8,24]$ & * \\
\hline & Wiry pulse & $\mathrm{A}[8,10,24], \mathrm{B}[8,24], \mathrm{C}[8], \mathrm{D}[24]$ & * \\
\hline
\end{tabular}

Chinese medicine classification and description of patterns and respective target-organs related to hypertension.

Legends: A: Liver-fire blazing upwards; B: Kidney-yin deficiency and Liver-yang rising; C: Obstruction of phlegm and dampness of Heart/Liver/Gallbladder; D: Qi and blood deficiency leading to Liver-yang rising; E: Kidney-yin/yang deficiency; CVD: cerebrovascular and eye disease; HD: heart disease; KD: kidney disease. Manifestations not considered as related to specific target-organs were marked as * and were not used for inference about target-organ damage.

bacterial species such as Solobacterium moorei which produces high levels of volatile sulfur compounds. Evidence suggested that even low concentrations of those compounds might be toxic and played a role in the link between oral infection and either heart [49] or cerebrovascular disease [50]. Conversely, the peeled (without coat) tongue was found to appear in subjects with healthy periodontal tissues [51]. The pallor observed in anemia, a common feature of chronic kidney failure
[42], was better identified at the tongue compared to conjunctivae, palms or nail beds and tongue pallor might rule out and modestly rule in severe anemia [52]. All remaining manifestations were not assigned to TOD and consequently not used in the current analysis. The resulting TODD was composed by 27 manifestations distributed among inspection $(n=4 ; 14.8 \%)$, auscultation-olfaction $(n=2 ; 7.4 \%)$, inquiry $(n=20 ; 74.1 \%)$ and palpation $(n=1 ; 3.7 \%)$. 


\section{Subject recruitment}

The study was conducted with a sample of patients from National Institute of Cardiology (Rio de Janeiro, Brazil) after the Medical Ethics Committee had approved the protocol (trial register number 0239/02.06.09). Written informed consent was obtained from all subjects in the study. Subjects newly diagnosed with hypertension were prospectively recruited from January 2009 to July 2009 (once a week) and admitted in this study after physical examination. The diagnostic criteria of hypertension were systolic and diastolic arterial blood pressure $\geq 140$ or $90 \mathrm{mmHg}$ respectively, measured in two or more consecutive visits at the outpatient clinic over a period of at least seven days [29]. Patients did not report a prior use of any antihypertensive. Metabolic diseases (such as diabetes mellitus) and secondary hypertension were clinically investigated and ruled out in all subjects. Sample sizes were estimated from formulae [53] designed for studies with correlation coefficient as the outcome. A minimum sample size of 36 cases is required to test for the alternative hypothesis that the correlation coefficient is higher than 0.41 (at least weak association) with $\alpha=5 \%$ (significance level) and $\beta=80 \%$ (power of test).

\section{Clinical variables and data measurement}

Forty-three subjects (among which 26 were female) with primary hypertension were enrolled in this study. All procedures were performed between 08:00 and 12:00 in a quiet room with controlled temperature $\left(19-21^{\circ} \mathrm{C}\right)$ immediately before the questionnaire interview. Ambulatory blood pressures were measured at the brachial artery (right arm) with a mercury column sphygmomanometer by the same examiner. The first and the fifth Korotkoff's phases were used to define SBP and DBP respectively. Mean blood pressure $(\mathrm{MBP}=2 / 3 \times \mathrm{DBP}$ $+1 / 3 \times \mathrm{SBP})$ and pulse pressure $(\mathrm{PP}=\mathrm{SBP}-\mathrm{DBP})$ were also calculated. Additional clinical parameters were also assessed, namely age, sex, body mass index (BMI) and heart rate (HR). Demographic data are in Table 2.

Interview with ZFHQ was performed with all subjects after clinical examination by the same Chinese medicine practitioner in the presence of another Chinese medicine doctor, each with ten years of clinical experience. The interviewer applied the ZFHQ to patients by asking them about the presence or absence of manifestations, marking them accordingly in each patient's printed questionnaire. Reports were digitized and converted to text data (string values, quoted terms and comma separated values) for analysis. Additionally, a photograph of the tongue from each patient was kept on record (Additional file 2).

Computer-based Chinese medicine pattern differentiation Patterns in both simulated and studied sample were identified with PDA $[37,38,54]$. PDA provides information of
Table 2 Characteristics of the studied sample

\begin{tabular}{|c|c|}
\hline Characteristics & Values \\
\hline Sample (Female; Male) & $43(26 ; 17)$ \\
\hline \multicolumn{2}{|l|}{ Clinical data, mean \pm SD } \\
\hline Age, years & $54.1 \pm 16.2$ \\
\hline Systolic pressure, $\mathrm{mmHg}$ & $\begin{array}{r}162.7 \pm \\
24.8\end{array}$ \\
\hline Diastolic pressure, $\mathrm{mmHg}$ & $98.6 \pm 16.6$ \\
\hline Mean pressure, $\mathrm{mmHg}$ & $\begin{array}{r}120.0 \pm \\
17.5\end{array}$ \\
\hline Pulse pressure, $\mathrm{mmHg}$ & $64.0 \pm 19.3$ \\
\hline Heart rate, $\mathrm{b} / \mathrm{min}$ & $70.9 \pm 12.4$ \\
\hline Body mass index, $\mathrm{kg} / \mathrm{m}^{2}$ & $27.1 \pm 6.3$ \\
\hline \multicolumn{2}{|l|}{ Zangfu patterns, N (\%) } \\
\hline Liver-fire blazing upwards & $5(11.6)$ \\
\hline Kidney-yin deficiency and Liver-yang rising & $33(76.7)$ \\
\hline $\begin{array}{l}\text { Obstruction of phlegm and dampness of Heart/Liver/ } \\
\text { Gallbladder }\end{array}$ & $0(0)$ \\
\hline Qi and blood deficiency leading to Liver-yang rising & $0(0)$ \\
\hline Kidney-yin/yang deficiency & 5 (11.6) \\
\hline \multicolumn{2}{|l|}{ Manifestations, median [minimum; maximum] } \\
\hline Presented (clinical history) & $\begin{array}{r}14.0[4.0 ; \\
23.0]\end{array}$ \\
\hline Available (used in pattern differentiation) & $\begin{array}{r}7.0[3.0 ; \\
10.0]\end{array}$ \\
\hline
\end{tabular}

Demographic and clinical variables of subjects with hypertension

diagnostic accuracy for testing with constructed datasets. PDA performs pattern differentiation with two quantitative criteria as follows.

(1) Explained information $\left(\mathrm{F}_{\%}\right)$ : calculated as the ratio between the count of manifestations found in each diagnostic hypothesis of the dataset and the total manifestations collected at the exam. This criterion indicates the 'strength' of the hypothesis as the actual diagnosis considering its predominance in the clinical history [54].

(2) Available information $\left(\mathrm{N}_{\%}\right)$ : calculated as the ratio between the count of manifestations found in each diagnostic hypothesis of the dataset and the total manifestations that describe the respective diagnostic hypothesis. A cutoff point may be subtracted from the $\mathrm{N}_{\%}$ value depending on the effect of the concave-shaped curve on PDA's accuracy [38]. This criterion indicates the 'strength' of the hypothesis as the actual diagnosis considering its predominance regarding the observed hypothesis.

PDA output indicated whether or not the pattern differentiation was successful. Automatic pattern differentiation was successful if a pattern presented the highest amount of explained manifestations $\left(\mathrm{F}_{\%}\right)$ with the concomitant lowest amount of manifestations $\left(\mathrm{N}_{\%}\right)$ among two or more diagnostic hypotheses. In other words, the identified pattern maximally explained the clinical history with minimum available information. In addition to 
the dichotomous output (success or failure), the output comprised a nominal variable (name of identified pattern) and two continuous, percent variables $\left(\mathrm{F}_{\%}\right.$ and $\mathrm{N}_{\%}$ criteria) indicating the strength of selection of pattern as a diagnostic hypothesis concerning presented and explained manifestations respectively.

\section{Computer-based TOD inference}

The present study inferred TOD occurrence with the same method and criteria used to differentiate patterns. In this case, the output for nominal (target-organ) and percent variables $\left(\mathrm{F}_{\%}\right.$ and $\left.\mathrm{N}_{\%}\right)$ referred to descriptions of TOD. Likewise, $\mathrm{F}_{\%}$ and $\mathrm{N}_{\%}$ indicated the strength of inference of the target-organ as damage concerning presented and explained manifestations respectively.

\section{Statistical Analysis}

\section{Diagnostic accuracy of the questionnaire}

The accuracy of ZFHQ was tested with the manifestation profile simulation algorithm (MPSA) described previously $[37,38,54]$ for the possibility to perform accurate pattern differentiation of hypertension-related patterns using PDA. Briefly, MPSA simulated true positive cases (TP) and true negative controls (TN) manifestation profiles from ZFHD with variable amount of manifestations $\mathrm{N}_{\%}$. The diagnosis identified by PDA was compared with the simulated condition. This process yielded a $2 \times$ 2 confusion matrix from which binomial estimators related to diagnostic accuracy are obtained with their respective $95 \%$ confidence intervals $(95 \% \mathrm{CI})$. The variable amount of information $\mathrm{N}_{\%}$ used by MPSA was then tested for optimum accuracy results by receiver operating curve analysis. A cutoff value for $\mathrm{N}_{\%}\left(\mathrm{~N}_{\% \text {-cutoff }}\right)$ was applied if a significant increase in accuracy was observed.

\section{Dataset analysis}

Similarity analysis between ZFHD and TODD was performed with the Jaccard coefficient $S_{J}$ [55] to test whether the descriptions of patterns in ZFHD were similar to descriptions of damage to target-organs in TODD. $S_{J}$ was in range $(0 ; 1)$, indicating no similarity (perfect dissimilarity) and perfect similarity respectively [56]. However, it would not be correct to infer strong similarity directly from high values of Jaccard's coefficient nor to infer weak similarity from low values because these values could be random. In turn, the random values expected to occur will depend on the number of attributes present in the sets formed by each pair of patterns and target-organs. Therefore, it was necessary to determine whether the values of Jaccard's coefficient in each pair differed from what would be expected at random in order to infer their significance. Thus, the null hypothesis was that the calculated $S_{\text {J }}$ between ZFHD and TODD was expected to occur at random and lower and upper critical values were obtained from tables [57] for acceptance of rejection of this null hypothesis considering the number of manifestations in either pattern and target-organ and the lowest number of manifestations in both pattern and target-organ descriptions. Since $S_{J}$ is a continuous variable that represent the 'strength' of association between both descriptions, it was categorized as an association measure [58], ie 0.00 (no similarity); 0.01 to 0.20 (negligible); 0.21 to 0.40 (weak); 0.41 to 0.70 (moderate); 0.71 to 0.99 (strong); 1.00 (perfect similarity).

\section{Clinical study analysis}

Frequencies of manifestations among patterns and in the whole sample were tabulated. PDA was used for pattern differentiation and estimation of prevalence of each pattern in the real cases sample. Additionally, both PDA's criteria $\mathrm{F}_{\%}$ and $\mathrm{N}_{\%}$ (both continuous variables) were also calculated for the association analysis described as follows. Pearson product moment correlation was used to calculate the association between the manifestations (dichotomous variables) and hemodynamic data (continuous variables). Pearson correlation coefficient $(r)$ was also used to calculate the association between patterns and TOD based on PDA's diagnostic criteria $\mathrm{F}_{\%}$ and $\mathrm{N}_{\%}$ obtained within ZFHD and TODD respectively. All candidate patterns as well as all possible target-organs output from PDA were considered simultaneously for this correlation analysis, ie each patient had their diagnostic criteria calculated by PDA for all Zangfu patterns and target-organs. Association was also categorized according to correlation coefficient [58], ie 0.00 (no association); 0.01 to 0.20 (negligible); 0.21 to 0.40 (weak); 0.41 to 0.70 (moderate); 0.71 to 0.99 (strong); 1.00 (perfect association). Null hypotheses were $r=0.00$ for all association tests. Statistical significance was considered at $P<0.05$.

\section{Computational resources}

All algorithms were implemented in LabVIEW 8.0 (National Instruments, USA) and executed on a 2.26 $\mathrm{GHz}$ Intel ${ }^{\circledR}$ Core 2 Duo microprocessor with $2.00 \mathrm{~GB}$ RAM running Windows 7 (Microsoft Corporation, USA).

\section{Results}

\section{Diagnostic accuracy of the questionnaire}

Two hundred subjects were simulated (100 true positive [TP] and 100 true negative [TN] per pattern) by MPSA using the FM, summing up 1,000 cases. No missing cases were found (all cases presented at least one manifestation). Diagnostic accuracy with $\mathrm{F}_{\%}$ yielded the following results: $\mathrm{TP}=481$, false positive $(\mathrm{FP})=1$, false negative $(\mathrm{FN})=19$ and $\mathrm{TN}=499$ cases; accuracy of $98.0 \%[97.3 ; 99.1]$; sensitivity and specificity of $96.2 \%$ 
[94.9; 98.3] and 99.8\% [99.6; 100.0] respectively; negative and positive predictive values of $96.3 \%$ [95.1; 98.4] and 99.8\% [99.6; 100.0] respectively. Diagnostic accuracy of PDA using $\mathrm{F}_{\%}$ and $\mathrm{N}_{\%}$ with the optimum cutoff value (19.0\% of manifestations) obtained for $\mathrm{N}_{\%}$ yielded the following: $\mathrm{TP}=487, \mathrm{FP}=6, \mathrm{FN}=13$ and $\mathrm{TN}=494$ cases; accuracy of $98.1 \%$ [97.4; 99.2]; sensitivity and specificity of 97.4\% [96.3; 99.2] and 98.8\% [98.2; 100.0] respectively; negative and positive predictive values of 97.4\% [96.4; 99.2] and 98.8\% [98.1; 100.0] respectively. No significant improvement $(P>0.05)$ was found on diagnostic accuracy with the cutoff values for $\mathrm{N}_{\%}$. Thus, no additional cutoff was applied to $\mathrm{N}_{\%}$ for pattern differentiation and TOD inference in the real patient sample.

\section{Similarity between ZFHD and TODD}

Similarity estimated between ZFHD and TODD is in Table 3 . There was a significant negligible $\left(S_{J} \leq 0.20\right)$ similarity in description between: Liver-fire blazing upwards pattern and both CVD $\left(S_{J}=0.15[0.19 ; 0.58]\right)$ and $\operatorname{HD}\left(S_{J}=0.12[0.13 ; 0.86]\right)$; Obstruction of phlegm and dampness of Heart/Liver/Gallbladder pattern and $\mathrm{KD}\left(S_{J}=0.11[0.16 ; 0.70]\right) ; q i$ and blood deficiency leading to Liver-yang rising pattern and both $\mathrm{HD}\left(S_{J}=0.00\right.$ $[0.07 ; 0.86])$ and $\mathrm{KD}\left(S_{J}=0.06[0.12 ; 0.86]\right)$; and Kidneyyin/yang deficiency pattern and both CVD $\left(S_{J}=0.15\right.$ $[0.19 ; 0.73])$ and HD $\left(S_{J}=0.06[0.12 ; 0.86]\right)$. No significant similarity was found between any other descriptions of patterns and TOD.

\section{Frequency of manifestations in hypertension}

Frequencies of manifestations grouped by identified hypertension-related pattern and whole sample are in Table 4. No pathognomonic manifestation was found among the whole sample of subjects with hypertension. Twelve manifestations presented high prevalence (> $50 \%)$, ie red tongue $(81.4 \%)$; headache $(72.1 \%)$; irritability (67.4\%); palpitation (60.5\%); blurred vision, insomnia, mental fatigue (58.1\%); frequent nocturnal urination, numbness in feet and hands, shortness of breath (55.8\%); and heavy limbs sensation, wiry pulse (51.2\%). However, 'red tongue' was present in all five subjects with Liver-fire blazing upwards pattern while 'numbness in feet and hands' appeared in all five subjects with Kidney-yin/yang deficiency pattern.

\section{Association between manifestations and hemodynamic variables}

SBP was weakly associated with excessive dreaming $(-0.398, P=0.008)$, shortness of breath $(-0.304, P=$ $0.047)$ and flushed face $(0.347, P=0.023)$. DBP was also weakly associated with flushed face $(0.306, P=0.046)$ as well as to palpitation $(0.355, P=0.019)$ and to thin pulse $(0.329, P=0.031)$. MBP was weakly associated with excessive dreaming $(-0.372, P=0.014)$. PP was weakly associated with pale tongue $(0.336, P=0.028)$, and conversely with red tongue $(-0.336, P=0.028)$, strong pulse $(0.304, P=0.048$ and shortness of breath $(-0.342, P=0.025)$. All other pairs of association were statistically no significant. After adjustment for age, sex and BMI, none of the above pairs exhibited statistically different values.

\section{Association between patterns and TOD}

Results of the association of the diagnostic criteria between patterns and TOD are in Table 5. In respect of information $\mathrm{F}_{\%}$, moderate association was observed between Liver-fire blazing upwards and KD $(0.424 ; P=$ 0.004 ) while weak association was found between Kidney-yin deficiency and Liver-yang rising with CVD $(-0.276 ; P=0.037)$ and HD $(-0.321 ; P=0.019)$ and $q i$ and blood deficiency leading to Liver-yang rising and HD $(0.322 ; P=0.019)$. No other comparison between pattern and TOD was significantly associated.

Regarding the amount of available information $\mathrm{N}_{\%}$, Liver-fire blazing upwards pattern was moderately

Table 3 Similarity between descriptions of Chinese medicine patterns and target-organs damage

\begin{tabular}{|c|c|c|c|c|c|}
\hline \multirow[b]{2}{*}{$\begin{array}{l}\text { Target- } \\
\text { organs } \\
\text { damage }\end{array}$} & \multicolumn{5}{|c|}{ Patterns } \\
\hline & $\begin{array}{l}\text { Liver-fire } \\
\text { blazing } \\
\text { upwards } \\
(\mathrm{n}=11)\end{array}$ & $\begin{array}{l}\text { Kidney-yin deficiency } \\
\text { and Liver-yang rising } \\
(n=13)\end{array}$ & $\begin{array}{l}\text { Obstruction of phlegm and } \\
\text { dampness of Heart/Liver/ } \\
\text { Gallbladder } \\
(n=10)\end{array}$ & $\begin{array}{l}\text { Qi and blood deficiency } \\
\text { leading to Liver-yang rising } \\
(n=7)\end{array}$ & $\begin{array}{l}\text { Kidney-yin/ } \\
\text { yang } \\
\text { deficiency } \\
(\mathrm{n}=11)\end{array}$ \\
\hline $\begin{array}{l}\text { CVD } \\
(n=19)\end{array}$ & $0.15^{*}[0.19 ; 0.58]$ & $0.23[0.19 ; 0.69]$ & $0.26[0.17 ; 0.70]$ & $0.30[0.15 ; 0.86]$ & $0.15^{*}[0.19 ; 0.73]$ \\
\hline $\begin{array}{l}\text { HD } \\
(n=7)\end{array}$ & $0.12^{*}[0.13 ; 0.86]$ & $0.11[0.11 ; 0.86]$ & $0.13[0.13 ; 0.86]$ & $0.00 *[0.07 ; 0.86]$ & $0.06^{*}[0.12 ; 0.86]$ \\
\hline $\begin{array}{l}\text { KD } \\
(n=11)\end{array}$ & $0.16[0.16 ; 0.72]$ & $0.14[0.14 ; 0.73]$ & $0.11^{*}[0.16 ; 0.70]$ & $0.06^{*}[0.12 ; 0.86]$ & $0.22[0.11 ; 0.73]$ \\
\hline
\end{tabular}

Jaccard coefficient of similarity between manifestations of patterns and target-organs damage calculated from ZFHD and TODD datasets.

* Values significantly lower than expected at random, $P<0.05$. All other values not different to those expected at random were left unmarked. Values in brackets represent critical values of $S$, with a probability level of $P<0.05$ considering the total number of manifestations present in either of the two patterns being compared and the minimum quantity of manifestations between patterns and target-organs. CVD: cerebrovascular and eye disease; HD: heart disease; KD: kidney disease. 
Table 4 Descriptive statistics of manifestations

\begin{tabular}{|c|c|c|c|c|}
\hline \multirow[t]{2}{*}{ Manifestations } & \multicolumn{4}{|c|}{ Frequency of manifestations } \\
\hline & $\begin{array}{c}\text { Liver-fire blazing } \\
\text { upwards } \\
\text { (n = 8; 18.6\%) }\end{array}$ & $\begin{array}{l}\text { Kidney-yin deficiency and Liver-yang } \\
\text { rising } \\
(\mathrm{n}=30 ; 69.8 \%)\end{array}$ & $\begin{array}{c}\text { Kidney-yin/yang } \\
\text { deficiency } \\
(n=5 ; 11.6 \%)\end{array}$ & $\begin{array}{l}\text { Whole sample } \\
(\mathrm{n}=43 ; 100 \%)\end{array}$ \\
\hline red tongue & $5(100.0)$ & $28(84.8)$ & $2(40.0)$ & $35(81.4)$ \\
\hline headache & $2(40.0)$ & $26(78.8)$ & $3(60.0)$ & $31(72.1)$ \\
\hline irritability & $2(40.0)$ & $27(81.8)$ & $0(0)$ & $29(67.4)$ \\
\hline palpitation & $1(20.0)$ & $21(63.6)$ & $4(80.0)$ & $26(60.5)$ \\
\hline blurred vision & $1(20.0)$ & $21(63.6)$ & $3(60.0)$ & $25(58.1)$ \\
\hline insomnia & $0(0)$ & $23(69.7)$ & $2(40.0)$ & $25(58.1)$ \\
\hline mental fatigue & $2(40.0)$ & $19(57.6)$ & $4(80.0)$ & $25(58.1)$ \\
\hline frequent nocturnal urination & $4(80.0)$ & $16(48.5)$ & $4(80.0)$ & $24(55.8)$ \\
\hline numbness in feet and hands & $0(0)$ & $19(57.6)$ & $5(100)$ & $24(55.8)$ \\
\hline shortness of breath & $2(40.0)$ & $19(57.6)$ & $3(60.0)$ & $24(55.8)$ \\
\hline heavy limbs sensation & $1(20.0)$ & $17(51.5)$ & $4(80.0)$ & $22(51.2)$ \\
\hline wiry pulse & $4(80.0)$ & $17(51.5)$ & $1(20.0)$ & $22(51.2)$ \\
\hline tinnitus & $2(40.0)$ & $16(48.5)$ & $3(60.0)$ & $21(48.8)$ \\
\hline red eyes & $2(40.0)$ & $14(42.4)$ & $4(80.0)$ & $20(46.5)$ \\
\hline constipation & $3(60.0)$ & $14(42.4)$ & $2(40.0)$ & $19(44.2)$ \\
\hline peeled tongue & $2(40.0)$ & $17(51.5)$ & $0(0)$ & $19(44.2)$ \\
\hline numbness in the limbs & $1(20.0)$ & $16(48.5)$ & $1(20.0)$ & $18(41.9)$ \\
\hline dizziness & $1(20.0)$ & $13(39.4)$ & $3(60.0)$ & $17(39.5)$ \\
\hline nausea & $1(20.0)$ & $15(45.5)$ & $1(20.0)$ & $17(39.5)$ \\
\hline $\begin{array}{l}\text { congested feeling in the } \\
\text { chest }\end{array}$ & $1(20.0)$ & $13(39.4)$ & $2(40.0)$ & $16(37.2)$ \\
\hline weak legs & $3(60.0)$ & $12(36.4)$ & $1(20.0)$ & $16(37.2)$ \\
\hline excessive dreaming & $0(0)$ & $10(30.3)$ & $1(20.0)$ & $11(25.6)$ \\
\hline flushed face & $1(20.0)$ & $8(24.2)$ & $2(40.0)$ & $11(25.6)$ \\
\hline thin pulse & $0(0)$ & $9(27.3)$ & $2(40.0)$ & $11(25.6)$ \\
\hline impotent & $1(20.0)$ & $7(21.2)$ & $2(40.0)$ & $10(23.3)$ \\
\hline strong pulse & $3(60.0)$ & $5(15.2)$ & $1(20.0)$ & $9(20.9)$ \\
\hline pale tongue & $0(0)$ & $5(15.2)$ & $3(60.0)$ & $8(18.6)$ \\
\hline vomiting & $0(0)$ & $7(21.2)$ & $1(20.0)$ & $8(18.6)$ \\
\hline fainting & $0(0)$ & $5(15.2)$ & $2(40.0)$ & $7(16.3)$ \\
\hline slippery pulse & $1(20.0)$ & $5(15.2)$ & $1(20.0)$ & $7(16.3)$ \\
\hline yellow coating & $3(60.0)$ & $4(12.1)$ & $0(0)$ & $7(16.3)$ \\
\hline fast pulse & $1(20.0)$ & $4(12.1)$ & $0(0)$ & $5(11.6)$ \\
\hline severe dizziness & $0(0)$ & $4(12.1)$ & $1(20.0)$ & $5(11.6)$ \\
\hline aphasia & $0(0)$ & $3(9.1)$ & $1(20.0)$ & $4(9.3)$ \\
\hline stroke & $1(20.0)$ & $2(6.1)$ & $1(20.0)$ & $4(9.3)$ \\
\hline deep pulse & $0(0)$ & $1(3.0)$ & $2(40.0)$ & $3(7.0)$ \\
\hline convulsions & $0(0)$ & $1(3.0)$ & $0(0)$ & $1(2.3)$ \\
\hline
\end{tabular}

Frequencies of manifestations in the studied sample according to Zangfu patterns (manifestations were arranged in decreasing order of occurrence). Values are shown as: absolute frequency (\%).

associated with all TOD (CVD: 0.606, $P<0.001$; HD: $0.650, P<0.001$; KD: 0.462, $P=0.002$ ). Kidney-yin deficiency and Liver-yang rising pattern was moderately associated with both CVD and HD $(0.637, P<0.001$; $0.590, P<0.001$, respectively) and weakly associated with KD $(0.311 ; P=0.029)$. Obstruction of phlegm and dampness of Heart/Liver/Gallbladder pattern was strongly associated with $\operatorname{CVD}(0.718, P<0.001)$ and moderately associated with both $\mathrm{HD}$ and $\mathrm{KD}(0.700, P<$ $0.001 ; 0.413, P=0.005$ respectively). $Q i$ and blood deficiency leading to Liver-yang rising pattern was strongly associated with $\mathrm{HD}(0.718, P<0.001)$ and moderately associated with KD $(0.651, P<0.001)$. Kidney-yin/yang deficiency pattern was moderately associated with CVD and HD $(0.584, P<0.001 ; 0.488, P=0.001$ respectively). All other comparisons yielded no significant association. 
Table 5 Association between ZFHD and TODD based on diagnostic criteria

\begin{tabular}{lllllll}
\hline $\begin{array}{l}\text { Target- } \\
\text { organ } \\
\text { damage }\end{array}$ & \begin{tabular}{lllll} 
Criterion \\
\cline { 2 - 7 }
\end{tabular} & $\begin{array}{l}\text { Liver-fire } \\
\text { blazing } \\
\text { upwards }\end{array}$ & $\begin{array}{l}\text { Kidney-yin deficiency } \\
\text { and Liver-yang rising }\end{array}$ & $\begin{array}{l}\text { Obstruction of phlegm and } \\
\text { dampness of Heart/Liver/ } \\
\text { Gallbladder }\end{array}$ & $\begin{array}{l}\text { Qi and blood deficiency } \\
\text { leading to Liver-yang } \\
\text { rising }\end{array}$ & $\begin{array}{l}\text { Kidney-yin/ } \\
\text { yang } \\
\text { deficiency }\end{array}$ \\
\hline CVD & $F_{\%}$ & -0.153 & $-0.276^{*}$ & -0.009 & 0.188 & -0.141 \\
& $N_{\%}$ & $0.606^{\dagger}$ & $0.637^{\dagger}$ & $0.718^{\dagger}$ & $0.651^{\dagger}$ & $0.584^{\dagger}$ \\
HD & $F_{\%}$ & -0.188 & $-0.321^{*}$ & -0.048 & $0.322^{*}$ & -0.263 \\
& $N_{\%}$ & $0.650^{\dagger}$ & $0.590^{\dagger}$ & $0.700^{\dagger}$ & $0.718^{\dagger}$ & $0.488^{\S}$ \\
KD & $F_{\%}$ & $0.424^{\S}$ & 0.087 & 0.124 & -0.244 & -0.096 \\
& $N_{\%}$ & $0.462^{\S}$ & $0.311^{*}$ & $0.413^{\S}$ & 0.248 & 0.234 \\
\hline
\end{tabular}

Pearson correlation coefficient calculated between diagnostic criteria $\mathrm{F}_{\%}$ and $\mathrm{N}_{\%}$ for each Zangfu pattern and target-organ in the studied sample. ${ }^{*} P<0.05 ;{ }^{5} P<0.01 ;{ }^{\dagger} P<0.001$. CVD: cerebrovascular and eye disease; HD: heart disease; KD: kidney disease.

\section{Discussion}

The main result of the present study is that Zangfu patterns were strongly or moderately associated with clinical manifestations of TOD in subjects with hypertension. Moreover, clinical manifestations were at most (all $\mathrm{r}<0.40$ ) weakly associated with hemodynamic variables.

\section{Relationship between Chinese medicine patterns and TOD in hypertension}

The results of this study indicated that all Zangfu patterns were strongly (up to $r=0.718$ ) or moderately associated with two or three target-organs due to hypertension by the amount of available information $\mathrm{N}_{\%}$. These results were much less (up to $r=0.424$ ) pronounced when association was tested with the explained information $\mathrm{F}_{\%}$ criterion. More interestingly, those results occurred in spite of the negligible similarity between theoretical descriptions in both ZFHD and TODD datasets. Altogether, these results indicate that the amount of information that explains a single pattern is directly proportional to the amount of information explained by the investigated target-organs for any quantity of manifestations in either clinical history or pattern. In other words, although patterns share no significant amount of manifestations with target-organs, the quantity of manifestations explained by a pattern is almost linearly proportional to the quantity of explained manifestations compatible with TOD in the same patient. The present study investigates such integrative relationship whereas other studies on morbidity of patterns in hypertension focused on descriptive statistics of patterns [27], therapeutic interventions [23-25] and proteomic analysis of dichotomous classes of patterns [26].

Chinese medicine pattern differentiation considers the presence or absence of manifestations in the exterior of the body, together with the individual constitutional characteristics, to differentiate the pattern inside the body, ie the internal organs and viscera. A pattern indicates the progress of a morbid condition at a certain phase, as well as the cause, nature, location, manifestation and prognosis of the condition. That is why different diseases may be associated with the same pattern and the same disease may be associated with different patterns [7-12]. The strength of this association is expected to vary with the similarity between descriptions of each pattern and disease (ie co-occurrence of manifestations) [38] and other factors such as relations to tissues, organs and systems functional interdependency, family history and environmental etiology [59].

In Chinese medicine, the amount of manifestations is a measure of the severity and progression of patterns [9], ie patterns under development are described by a small amount of manifestations (low $\mathrm{N}_{\%}$ values) while severe patterns usually presents with a large amount of manifestations (high $\mathrm{N}_{\%}$ values). The explained information criterion is based on the holistic approach that 'all manifestations must be interpreted collectively' $[9,54]$ and thus is more influenced by co-occurrence than $\mathrm{N}_{\%}$, which explains the strong correlation found between patterns and TOD with $\mathrm{N}_{\%}$ but not with $\mathrm{F}_{\%}$.

By contrast, in conventional medicine, subclinical findings of diseases must be assessed with clinical and laboratorial examinations. The presence of 'silent', asymptomatic TOD (eg left ventricle hypertrophy, carotid atherosclerosis, diminished glomerular filtration rate, increased serum creatinine and microalbuminuria) in subjects with hypertension is already an indicator of disease progression. Silent TOD is estimated to occur in in $61.3 \%$ (any TOD) of subjects with hypertension while $50.3 \%$ of the hypertensive patients presented a single silent TOD, $31.0 \%$ two TOD and $18.7 \%$ presented three or more [60]. If left untreated, subclinical hypertension may lead to localized microvascular lesions (atherosclerosis) which can progress into diffuse (arteriosclerosis) lesions, affecting target-organs and producing various manifestations [32], ie silent TOD slowly progresses to symptomatic TOD. Because of the progression of structural damages, hypertension can be undiscovered for 10-20 years [61] and the overall 
prevalence of clinically manifested TOD can be as high as $95 \%$ for stroke (CVD), $89 \%$ for left ventricular hypertrophy (HD) and 95\% for kidney failure (KD) [62]. Although this study does not present data regarding silent TOD to guarantee that patients actually present any degree of TOD - in fact, for some manifestations is not quite necessary (eg stroke) - the collective results of this first study strongly indicate that the five Zangfu patterns commonly used for pattern differentiation in patients with hypertension are indeed related to hypertension-induced TOD. Further studies should focus on subclinical findings in hypertension and their relationship with symptomatic hypertensive patients and Chinese medicine patterns.

\section{Frequency distribution of patterns and manifestations}

The frequency distribution of patterns observed in this sample is in agreement with previously studies. Maklin et al. [24] reported that Kidney-yin deficiency and Liveryang rising (shen yin xu gan yang shang yan) was the most prevalent pattern (47-63\%), followed by obstruction of phlegm and dampness of Heart/Liver/Gallbladder (xin gan dan shi tan bi) (19-30\%), Liver-fire blazing upwards (gan huo shang yan) (13-17\%), qi and blood deficiency leading to Liver yang rising (qi xue xu gan yang shang yan) (2-6\%) and Kidney-yin/yang deficiency (shen yin yang $x u)(0-3 \%)$. Gu et al. [27] found stagnation of phlegm-dampness (zhi shi tan) to be the most prevalent pattern (27\%), followed by hyperactivity of the Liver-yang (gan yang shang yan) (24\%), deficiency of Heart/Kidney-Qi (xin shen qi xu) (10\%), blood stasis obstructing the collaterals (luo xue yu bi) (9\%), deficiency of yin and yang (yin yang $x u$ ) (8\%) while other syndromes accounted for $21 \%$ of the sample. Why patterns related to Liver-yang and phlegm-dampness are the most prevalent is still unknown. Emotional states, family history and food habits play important roles in the etiology of these patterns and are considered as major risk factors to hypertension by both Chinese medicine $[9,11]$ and conventional medicine [29].

\section{Association between manifestations, patterns, and hemodynamic data}

High blood pressure levels should be symptomless; however, patients and physicians usually attribute symptoms to increased levels of blood pressure. The weak significant association between manifestations and blood pressure variables observed in this study were not held under adjustment for age, sex and BMI. These results agree with the physiologic knowledge on blood pressure control and with other epidemiologic reports according to which symptoms were not significantly correlated to hypertension [63,64], patterns [27] or proved uncorrelated when adjusted to confounding variables [65] or awareness of hypertension [66]. In the present study, association tests were performed with the entire sample of hypertensive subjects. It is possible that predominance of Kidney-yin deficiency and Liver-yang rising pattern lead to biased results. Further studies may search for such correlations with the sample divided into equally distributed subgroups regarding all identified patterns and subsample sizes.

\section{Using manifestations to bridge the gap between Chinese medicine and conventional medicine}

The present study regards the patient as the common element to both medical practices. Chinese medicine practitioners and physicians interpret clinical manifestations according to their medical training and may not rely on information provided by laboratories and medical imaging. Conventional medicine considers the manifestations of hypertension-induced TOD as consequences of progressive, structural lesions to arteries that progressively compromise blood flow to and cell metabolism of vital organs. Chinese medicine interprets the same manifestations as due to chronic, functional imbalances of organs and viscera that result in Zangfu deficiency states and obstruction or rebellion of $q i$, yin, yang or blood (xue). Risk factors for hypertension are quite identical in these two medical systems and stress the observed strong association between TOD with manifestations and Zangfu patterns.

Implications for proper antihypertensive agents selection While current pharmacological treatment for hypertension is based on the level of SBP and DBP and the level of total cardiovascular risk [29], however, Chinese medicine diagnosis with disease subtyping may provide insights into optimization of classes of antihypertensive medications for TOD management. For instance, research suggests that specific agents work better in treating hypertension with particular patterns, eg calcium channel blockers for phlegmatic damp excess pattern and blood stasis; $\beta$-blockers for liver-yang rising; angiotensin converting enzyme inhibitors for yin-deficiency and yang-hyperactivity or combined liver-yin and kidney-yin deficiency [22]. The therapeutic potential of several antihypertensive agents (diuretics, angiotensin converting enzyme inhibitors, angiotensin II receptor antagonists, $\beta$-blockers, calcium channel blockers and aldosterone antagonism) have been shown to also improve hypertension-induced TOD [32]. However, the efficacy of antihypertensive agents, acupuncture and herbs as well as the effects of such interventions on TOD is yet to be determined.

\section{Conclusion}

Zangfu patterns are associated with clinical manifestations of TOD. Manifestations associated patterns 
indicate morbid conditions to be secondary to hypertension rather than simple blood pressure.

\section{Additional material}

Additional file 1: Zangfu patterns hypertension dataset (ZFHD). This table presents the complete description of manifestations regarding Zangfu patterns and distributed among the Examination methods

Additional file 2: Representative cases for each Zangfu pattern in hypertension. This table presents a representative case for each diagnosis, including its manifestations and tongue pictures for illustration of cases.

\section{Abbreviations}

95\%Cl: 95\% confidence interval; BMl: body mass index; CVD: cerebrovascular and eye disease; DBP: diastolic blood pressure; $F_{\%}$ : proportion of explained information of pattern from clinical history; FM: Four methods; FN: false negative; FP: false positive; HD: heart disease; HR: heart rate; KD: kidney disease; MBP: mean blood pressure; MPSA: manifestation profile simulation algorithm; No\%: proportion of available information of pattern in dataset; $\mathrm{N}$ \%-cutoff: proportion of optimized available information of pattern in dataset; PDA: pattern differentiation algorithm; PP: pulse pressure; $r$ : Pearson correlation coefficient; SBP: systolic blood pressure; S;: Jaccard coefficient of similarity; STROBE: Strengthening the Reporting of Observational Studies in Epidemiology; TN: true negative; TOD: target-organ damage; TODD: targetorgan disease dataset; TP: true positive; ZFHD: Zangfu hypertension dataset; ZFHQ: Zangfu hypertension questionnaire.

\section{Acknowledgements}

The authors would like to acknowledge the helpful comments from the reviewers and editor. Trial registration: Australian New Zealand Clinical Trials Register ACTRN12609000933257.

\section{Author details}

'Amarina Motta School Clinic, Augusto Motta University Center, Av. Paris 72, Bonsucesso, Rio de Janeiro, BR CEP 21041-020, Brazil. " Division of Arterial Hypertension, National Institute of Cardiology, Rua das Laranjeiras 374, Laranjeiras, Rio de Janeiro, BR CEP 22240-006, Brazil. ${ }^{3}$ Department of Cardiology, Medical School, Gama Filho University, Rua das Laranjeiras 374, Laranjeiras, Rio de Janeiro, BR CEP 22240-006, Brazil. ${ }^{4}$ Program of Rehabilitation Science, Centro Universitário Augusto Motta, Praça das Nações 34, Bonsucesso, Rio de Janeiro, BR CEP 21041-010, Brazil.

\section{Authors' contributions}

ASF designed the study, developed the computational methods for pattern differentiation, performed the statistical analysis and drafted the manuscript. $A B L$ performed literature review and questionnaire interview. JBF and IC evaluated and diagnosed the patients for enrollment in the study. All authors revised and approved the final version of the manuscript.

\section{Competing interests}

The authors declare that they have no competing interests.

Received: 28 February 2011 Accepted: 17 June 2011

Published: 17 June 2011

\section{References}

1. Yang SZ, Li JY: Treatise on the Spleen \& Stomach Boulder, Colorado: Blue Poppy Press; 1993.

2. Yang SZ, Chace C: The Systematic Classic of Acupuncture \& Moxibustion Boulder, Colorado: Blue Poppy Press; 2004

3. Luo XW: Synopsis of Prescriptions of the Golden Chamber with 300 Cases Beijing: New World Press; 1995.

4. Yang SZ: Master Hua's Classic of the Central Viscera Boulder, Colorado: Blue Poppy Press; 2003
5. Meier PC, Rogers C: Reporting traditional Chinese medicine morbidity - A University of Technology, Sydney, project with an emphasis on developing standards for testing and reporting data. J Altern Complement Med 2006, 12:529-534.

6. Meier $P C$, Rogers $C$ : The need for traditional Chinese medicine morbidity research. Complement Ther Med 2007, 15:284-288.

7. O'Connor J, Bensky D: Acupuncture a Comprehensive Text Seattle: Eastland Press; 1987.

8. Auteroche B, Navailh P: O Diagnóstico na Medicina Chinesa São Paulo: Andrei; 1992.

9. Maciocia G: Os Fundamentos da Medicina Chinesa: Um Texto Abrangente para Acupunturistas e Fitoterapeutas São Paulo: Roca; 1996.

10. Yamamoto C: Pulsologia: Arte e Ciência do Diagnóstico na Medicina Oriental. 2 edition. São Paulo: Ground; 1998.

11. Ross J: Combinação Dos Pontos de Acupuntura: a Chave para o Exito Clínico São Paulo: Roca; 2003.

12. Maciocia G: Diagnóstico na Medicina Chinesa: Um Guia Geral São Paulo: Roca; 2006.

13. Yu SY, Zhang L, Yang JX, Qian ZK, Peng YW: Dialectic classification of syndrome diagnosis in traditional Chinese medicine used as new criterion for evaluating prognosis of patients with cervical cancer. $J$ Huazhong Univ Sci Technolog Med Sci 1991, 11:123-125.

14. Alrækb T, Aunea A, Baerheimb A: Traditional Chinese medicine syndromes in women with frequently recurring cystitis: frequencies of syndromes and symptoms. Complement Ther Med 2000, 8:260-265.

15. Zhang Q, Liu P, Cheng HF, Chen L, Cao SH, lu Y, Wei JJ, Fang ZH, Wu DZ: Clinical investigation on characteristics of traditional Chinese medical syndrome of hepatocirrhosis. Zhong Xi Yi Jie He Xue Bao 2003, 1:108-112.

16. Chen XR, Li GM, Wang JR, Chen JJ: Portal hemodynamics in patients with different syndromes of cirrhosis. Zhong Xi Yi Jie He Xue Bao 2004, 2:178-181.

17. Sun DZ, Lui L, Jiao JP, Wei PK, Jiang LD, Xu L: Syndrome characteristics of traditional Chinese medicine: summary of a clinical survey in 767 cases of gastric cancer. Zhong Xi Yi Jie He Xue Bao 2010, 8:332-340.

18. Kearney PM, Whelton M, Reynolds K, Muntner P, Whelton PK, He J: Global burden of hypertension: analysis of worldwide data. Lancet 2005, 365:217-223.

19. Jia ZH, Li YS, Wu YL, Gao HL, Chen J, Chen JX, Gu CH, Yuan GQ, Wu XC, Wei C: Extraction, combination and distribution regularity of syndrome elements in patients with variant angina pectoris. Zhong $X_{i} Y_{i}$ Jie He Xue Bao 2007, 5:616-620.

20. Wang J, He QY: Laws of syndrome element combination in stable angina pectoris: a study based on cluster analysis and correspondingcorrelation analysis. Zhong Xi Yi Jie He Xue Bao 2008, 6:690-694.

21. You JS, Huang Y, Guo JW, Liang WX, Huang PX, Liu MC: Characteristics of traditional Chinese medicine syndromes in patients with acute ischemic stroke of yin or yang syndrome: a multicenter trial. Zhong $X_{i} Y_{i}$ Jie He Xue Bao 2008, 6:346-351.

22. Gu WL, Cao Y, Shi ZX, Hui KK: Potential of using pattern diagnosis of traditional Chinese medicine to improve the clinical use of antihypertensive agents. Zhong Xi Yi Jie He Xue Bao 2007, 5:255-258.

23. Kalish LA, Buczynskib B, Connella P, Gemmela A, Goertzc C, Macklina EA, Pian-Smithd M, Stevensa S, Thompsond J, Valaskatgisf P, Waynef PM, Zusman RM: Stop Hypertension with the Acupuncture Research Program (SHARP): clinical trial design and screening results. Control Clin Trials 2004, 25:76-103.

24. Macklin EA, Wayne PM, Kalish LA, Valaskatgis P, Thompsom J, PianSmith MCM, Zhang Q, Stevens S, Goertz C, Prineas RJ, Buczynski B, Zusman RM: Stop Hypertension With the Acupuncture Research Program (SHARP): Results of a randomized, controlled clinical trial. Hypertension 2006, 48:838-845.

25. Flachskampf FA, Gallasch J, Gefeller O, Gan J, Mao J, Pfahlberg AB, Wortmann A, Klinghammer $L$ : Randomized trial of acupuncture to lower blood pressure. Circulation 2007, 115:3121-3129.

26. Chu YG, Shi J, Hu YH, Wu HQ, Liu GJ, Hu CH, Li YZ, Li Y, Chen ZJ, He Q Serum proteomes of hypertension patients with abundant phlegmdampness. Zhong Xi Yi Jie He Xue Bao 2009, 7:629-635.

27. Gu WL, Shi ZX, Yu YX, Wu YW, Lu BW, Hui KK: Distribution characteristics of syndrome types in essential hypertension. Zhong $X_{i} Y_{i}$ Jie He Xue Bao 2010, 8:842-847. 
28. Chobanian AV, Bakris GL, Black HR, Cushman WC, Green LA, Izzo JL, Jonse DW, Materson BJ, Oparil S, Wright JT Jr, Roccella EJ: The seventh report of the Joint National Committee on prevention, detection, evaluation, and treatment of high blood pressure: the JNC 7 report. Am Med Assoc 2003, 289:2560-2572.

29. Mancia G, De Backer G, Dominiczak A, Cifkova R, Fagard R, Germano G, Grassi G, Heagerty AM, Kjeldsen SE, Laurent S, Narkiewicz K, Ruilope L, Rynkiewicz A, Schmieder RE, Struijker Boudier HA, Zanchetti A, Vahanian A, Camm J, De Caterina R, Dean V, Dickstein K, Filippatos G, Funck-Brentano C, Hellemans I, Kristensen SD, McGregor K, Sechtem U, Silber S, Tendera M, Widimsky P, Zamorano JL, Kjeldsen SE, Erdine S, Narkiewicz K, Kiowski W, Agabiti-Rosei E, Ambrosioni E, Cifkova R, Dominiczak A, Fagard R, Heagerty AM, Laurent S, Lindholm LH, Mancia G, Manolis A, Nilsson PM, Redon J, Schmieder RE, Struijker-Boudier HA, Viigimaa M, Filippatos G, Adamopoulos S, Agabiti-Rosei E, Ambrosioni E, Bertomeu V, Clement D, Erdine S, Farsang C, Gaita D, Kiowski W, Lip G, Mallion JM, Manolis AJ, Nilsson PM, O'Brien E, Ponikowski P, Redon J, Ruschitzka F, Tamargo J, van Zwieten P, Viigimaa M, Waeber B, Williams B, Zamorano JL: Guidelines for the management of arterial hypertension: The task force for the management of arterial hypertension of the European Society of Hypertension (ESH) and of the European Society of Cardiology (ESC). J Hypertens 2007, 25:1105-1187.

30. Antonios TFT, Singer DRJ, Markandu ND, Mortimer PS, MacGregor GA: Structural skin capillary rarefaction in essential hypertension. Hypertension 1999, 33:998-1001.

31. Hernández N, Torres SH, Finol HJ, Vera O: Capillary changes in skeletal muscle of patients with essential hypertension. Anat Rec A Discov Mol Cell Evol Biol 1999, 256:425-432.

32. Cohuet G, Struijker-Boudier H: Mechanisms of target organ damage caused by hypertension: Therapeutic potential. Pharmacol Ther 2006, 111:81-98.

33. Ferreira AS, Santos MAR, Barbosa Filho J, Cordovil I, Souza MN: Determination of radial artery compliance can increase the diagnostic power of pulse wave velocity measurement. Physiol Meas 2004, 25:37-50.

34. Heistad DD, Armstrong ML, Baumbach GL, Faraci FM: Sick vessel syndrome - Recovery of atherosclerotic and hypertensive vessels. Hypertension 1995, 26:509-513.

35. Rutherford RB: Vascular Surgery. 4 edition. Pensilvania: Saunders Company; 1995.

36. Vandenbroucke JP, von Elm E, Altman DG, Gøtzsche PC, Mulrow CD, Pocock SJ, Poole C, Schlesselman JJ, Egger M: Strengthening the Reporting of Observational Studies in Epidemiology (STROBE): Explanation and elaboration. Ann Intern Med 2007, 147:W163-W194.

37. Ferreira AS: Diagnostic accuracy of pattern differentiation algorithm based on traditional Chinese medicine theory: a stochastic simulation study. Chin Med 2009, 4:24.

38. Ferreira AS: Misdiagnosis and undiagnosis due to pattern similarity in Chinese medicine: a stochastic simulation study using pattern differentiation algorithm. Chin Med 2011, 6:1.

39. Carter JE: Chronic ocular ischemia and carotid vascular disease. Stroke $1985,16: 721-728$.

40. Klaassen-Broekema $\mathrm{K}$, van Bijsterveld $\mathrm{OP}$ : Red eyes in renal failure. $\mathrm{Br} J$ Ophthalmol 1992, 76:268-271

41. Hafeez F, Levine RL, Dulli DA: Pulsatile tinnitus in cerebrovascular arterial diseases. J Stroke Cerebrovasc Dis 1999, 8:217-223.

42. Astor BC, Muntner P, Levin A, Eustace JA, Coresh J: Association of kidney function with anemia. The third National Health and Nutrition Examination Survey (1988-1994). Arch Intern Med 2002, 162:1401-1408.

43. Shayne PH, Pitts SR: Severely increased blood pressure in the emergency department. Ann Emerg Med 2003, 41:513-529.

44. Murtagh FEM, Addington-Hall JM, Edmonds PM, Donohoe P, Carey I, Jenkins K, Higginson IJ: Symptoms in advanced renal disease: A crosssectional survey of symptom prevalence in stage 5 chronic kidney disease managed without dialysis. J Palliat Med 2007, 10:1266-1276.

45. Noble H, Meyer J, Bridges J, Johnson B, Kelly D: Exploring symptoms in patients managed without dialysis: a qualitative research study. J Ren Care 2010, 36:9-15.

46. Pinkney-Atkinson VJ, Milne J: Referring hypertensive patients with target organ damage - a clinical guide for nurses. Prof Nurs Today 2007, 11:20-22.
47. Taylor DJ, Mallory L, Lichstein KL, Durrence HH, Riedel BW, Bush AJ: Comorbidity of chronic insomnia with medical problems. Sleep 2007, 30:213-218.

48. Li ZG: Comparative study on WHO western pacific region and world federation of Chinese medicine Societies international standard terminologies on traditional medicine: an analysis of the Diagnostics (Part 7). Zhong Xi Yi Jie He Xue Bao 2010, 8:292-297.

49. Haraszthy VI, Zambon JJ, Sreenivasan PK, Zambon MM, Gerber D, Rego R, Parker C: Identification of oral bacterial species associated with halitosis. J Am Dent Assoc 2007, 138:1113-1120.

50. Awano S, Ansai T, Takata Y, Soh I, Yoshida A, Hamasaki T, Kagiyama S, Nakamichi I, Sonoki K, Takehara T: Relationship between volatile sulfur compounds in mouth air and systemic disease. J Breath Res 2008, 2:017012 (4pp).

51. Danser MM, Gómez SM, Van der Weijden GA: Tongue coating and tongue brushing: a literature review. Int J Dent Hyg 2003, 1:151-158.

52. Kalantri A, Karambelkar M, Joshi R, Kalantri S, Jajoo U: Accuracy and reliability of pallor for detecting anaemia: A hospital-based diagnostic accuracy study. PLOS ONE 2010, 5:e8545.

53. Zou KH, Tuncali K, Silverman SG: Correlation and simple linear regression. Radiology 2003, 227:617-628.

54. Ferreira Ade S: Statistical validation of strategies for Zang-Fu single pattern differentiation. Zhong Xi Yi Jie He Xue Bao 2008, 6:1109-1116.

55. Jaccard P: Étude comparative de la distribution florale dans une portion des Alpes et des Jura. Bull Soc Vaud Sci Nat 1901, 37:547-579.

56. Real $R$, Vargas JM: The probabilistic basis of Jaccard's index of similarity. Syst Biol 1996, 45:380-385.

57. Real R: Tables of significant values of Jaccard's index of similarity. Miscellània Zoològica 1999, 22:29-40.

58. World Health Organization: Health Research Methodology: a Guide for Training in Research Methods. 2 edition. Genebra; 2001.

59. Guang JY: The mode of thinking in Chinese clinical medicine: characteristics, steps and forms. Clin Acupunct Orient Med 2001, 2:23-28.

60. Segura J, De La Sierra A, Fernandez S, Ruilope LM: High prevalence of target organ damage in hypertensive and prehypertensive patients with associated cardiovascular risk. J Hypertens 2010, 28:e466.

61. Braunwald E, Zipes DP, Libby P: Heart Disease: A Textbook of Cardiovascular Medicine. 6 edition. Philadelphia: W. B. Saunders Company; 2001.

62. Noblat ACB, Lopes MB, Lopes AA: Raça e Lesão de Órgãos-Alvo da Hipertensão Arterial em Pacientes Atendidos em um Ambulatório Universitário de Referência na Cidade de Salvador. Ara Bras Cardiol 2004, 82:111-115.

63. Fasce $E$, Flores $M$, Fasce F: Prevalence of symptoms associated with blood pressure in normal and hypertensive population. Rev Med Chil 2002, 130:160-166.

64. Fuchs FD, Gus M, Moreira LB, Moreira WD, Gonçalves SC, Nunes G: Headache is not more frequent among patients with moderate to severe hypertension. J Hum Hypertens 2003, 17:787-790.

65. Kottke TE, Tuomilehto J, Puska P, Salonen JT: The relationship of symptoms and blood pressure in a population sample. Int J Epidemio 1979, 8:355-359.

66. Di Tullio M, Alli C, Avanzini F, Bettelli G, Colombo F, Devoto MA, Marchioli R, Mariotti G, Radice M, Taioli E, Tognoni G, Villella M, Zussino A, for the Gruppo di Studio Sulla Pressione Arteriosa Nell'Anziano: Prevalence of symptoms generally attributed to hypertension or its treatment: study on blood pressure in elderly outpatients (SPAA). J Hypertens 1988, 6:587-590.

doi:10.1186/1749-8546-6-23

Cite this article as: Luiz et al:: Zangfu zheng (patterns) are associated with clinical manifestations of zang shang (target-organ damage) in arterial hypertension. Chinese Medicine 2011 6:23. 